\title{
Need For Leadership: Empirical Evidence From Pakistan
}

Mahmood A Bodla, COMSATS Institute of Information Technology, Sahiwal, Pakistan Ghulam Hussain, COMSATS Institute of Information Technology, Sahiwal, Pakistan

\begin{abstract}
Abundant research has been carried out throughout the years to explore the moderator effect of situational variables in leadership literature around the globe. However, this area is the most neglected area among the behavioral scientists of Pakistan. Therefore, the present study seeks to find out the moderator effect of need for leadership in relation with leadership characteristics on subordinates' behavioral outcomes using the need for leadership framework of de Vries (1997) in Pakistani work settings. As a result, the practical implications of the findings are discussed.
\end{abstract}

Keywords: Need for leadership, leadership characteristics, followers, outcomes

\section{INTRODUCTION}

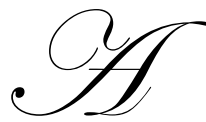

decade ago, de Vries (1997) suggested that need for leadership prevails in each follower and this need influences leadership efforts in predicting the subordinates work outcomes. According to author, need for leadership is a social, contextual, and quasi need (p. 92) which is linked with variety of individual's, task and organizational characteristics simultaneously that affect leadership efforts on subordinates' behaviors.

First, need for leadership is ascribed as a social need. The term social refers; this need is stimulated among individuals while working in a group. According to McClelland (1955), people acquire different needs as result of social interactions with others. It is clear that most of the employees' work related activities are performed in a group. While working in groups, people develop strong sense of belongingness with each other and try to perform certain activities which are in interest of common goal. In these groups, some people play the role of leaders, while others act as subordinates. According to de Vries (1997), the need which is provoked by the leader among subordinates due to his position power or the need activated among individuals adhering to group's goal is need for leadership.

Second, need for leadership is a contextual need. Contextual refers to work environment and type of work individuals have to perform. According to House (1971), in case of highly professional jobs, where tasks are ambiguous and methodological variant and work activities are non routine, subordinates may feel insecure due to role ambiguity and have strong desire for leaders' interventions which serve to reduce the role ambiguity. Whereas, in case of routine and dull tasks, followers may desire social support from their leaders. In both situations, desiring different leadership (e.g. instrumental leadership or supportive leadership) by followers reflect the situational aspects of need for leadership. Besides the work settings, followers' characteristics are also important for determining the need for leadership. For example, trained, experienced, and qualified employees require less hierarchical guidance (i.e. need for leadership) than their less able and less trained colleagues (Kerr and Jermier, 1978).

Third, need for leadership is a quasi need. Quasi refers to the position of need for leadership that it takes place. Unlike the primary needs e.g. hunger, thirst or shelter needs postulated by Maslow (1943), this need is a secondary need and mainly related to mental activities (De Vries, 1997).

Several reasons exist for studying need for leadership theory. First, need for leadership construct has offered the concept of using single moderator variable in leadership research contrary to others e.g. substitutes for 
leadership (Kerr and Jermier, 1978). The proponents of this theory claimed by using single moderator variable; researchers can get more profound moderator results. More deeply, when different variables are used as moderator variables (e.g. substitutes for leadership), the variation in their reliability scores affect the power of statistical techniques to detect the moderator affects, and as a result, moderator effects are underestimated opposing to the expectations. While using one variable, reliability score remains constant for all relationships and ultimately results in improved ways.

Second, understanding the degree and type of need for leadership among followers will have profound effect on managerial practices. Based on the need for leadership of followers, leadership will be given to followers. Thus, understanding the followers' need for leadership and then adopting appropriate leadership style will result in more effectual leadership practices. In this way, unnecessary and redundant leaders' behaviors can be minimized.

Third, earlier work on need for leadership and others closely related concepts include the empirical evidence from Western work organizations and no empirical evidence could be obtained from the Pakistani work organizations. Due to cultural differences, in the developed industrial societies and underdeveloped or developing societies, it becomes virtually impossible to generalize the findings of earlier studies in Pakistani context. Therefore, the present study is designed in Pakistani work settings and aims to find out the impact of followers' need for leadership in combination with leadership characteristics on subordinates' work outcomes especially in banking sector of Pakistan.

\section{LITERATURE REVIEW}

De Vries (1997) conducted various studies in diverse organizational work settings in Netherlands to find out the moderator effects of need for leadership on the relationship between leadership characteristics and outcomes. The empirical results of these studies are separately discussed below.

In a first study of 345 insurance agents, need for leadership was found as enhancer of the relationship between human oriented leadership and followers' satisfaction. While in case of task oriented leadership and commitment, despite the task oriented leadership was negatively related to followers' commitment, need for leadership was found as a positive predictor of followers' commitment.

In a second study of 336 insurance agents, no interaction term of need for leadership and leadership characteristics was found statistically significant. However, need for leadership was found only a positive predictor of the outcomes criteria.

In a third study of 386 employees from municipalities, in the first case, need for leadership was found as reverser of the relationship between task oriented leadership and followers' satisfaction. In second case, need for leadership was found as simple positive moderator of the relationship between human oriented leadership and followers' commitment. While in case of human oriented leadership and followers' satisfaction, it was found as negative predictor of followers' satisfaction.

In a fourth and final study, a diverse sample of 958 employees from different work organizations was utilized. In order to explore the interaction effects of need for leadership and leadership characteristics on outcomes, separate analyses were performed for each possible relationship. The empirical results of satisfaction outcome criterion showed that need for leadership was found as a reducer of the relationship between leadership characteristics (charismatic leadership and leader's expertise) and followers' satisfaction. While in case of human oriented leadership and satisfaction, despite of the positive relation, need for leadership was negatively related to followers' satisfaction.

The statistical results of commitment on leadership characteristics, need for leadership and their interactions revealed that in cases of leader's expertise and task oriented leadership, need for leadership was found as simple positive moderator. While, in case of charismatic leadership, need for leadership was found as reducer of the relationship between charismatic leadership and followers' commitment. The empirical results of performance on human oriented leadership and need for leadership revealed that need for leadership was a pure negative 
moderator of the relationship between human oriented leadership and performance.

In the light of above discussion, the present study will test the main hypothesis of de Vries (1997) study.

Hypothesis: Need for leadership will moderate the relationship between leadership characteristics and subordinates work outcomes.

In order to empirically test the above mentioned hypothesis, the next section describes the research methodology.

\section{RESEARCH METHODOLOGY}

\subsection{Population and Sample}

Banking sector has been chosen as a target population for the current study. First, it is a growing sector and has gone through major changes, such as technological revolution (ATM, mobile banking, e-banking), human resource training and transformation, growing competition because of the increased influx of multinational banks in Pakistani market during the last few years. Due to these modern changes, the work environment of banking sector closely resembles with the work environment of Western Organizations. Second, the banking sector of Pakistan is subject to continuous improvements in banking laws and operating procedures by law enforcement agencies and Central Bank of Pakistan. Such changing environment has been posing additional burden on banks leaders in meeting needs at the individuals, groups and, organizational level. Thus, this sector is considered to be well suited to empirically testing of this Western theory in Pakistani context.

In order to obtain a representative sample, at the first stage, 550 branches of different banks in the Punjab province were selected as target population for the study. At second stage, officers grade employees were chosen as targeted respondents.

\subsection{Data Collection Methodology}

Data were collected through self administered questionnaires. Questionnaire consisted of four parts. In the first part, general information about the respondents were inquired. In the second part, employees were asked to evaluate their need for leadership in different situations. In the third part, leadership practices of their managers were rated by the respondents. In the last and fourth part, respondents were asked to rate their overall performance, satisfaction and commitment with their respective banks.

To obtain a good number of responses, 850 questionnaires were administered to the targeted employees. Out of which 364 were retrieved (yielding a $43 \%$ response rate). Some questionnaires were found incomplete and were excluded from analysis, and as such, 313 questionnaires, complete in all respects, were usable for analysis purpose.

\subsection{Measures}

Need for leadership: Need for leadership is defined as "The extent to which employee wishes the leader to facilitate or clear his/her path towards individuals, group or organizational goal” (de Vries, 2002).

Need for leadership of the followers was measured by 17 items of de Vries (1997) and cronbach alpha value was 0.89 for this study. These items were measured on 5 point scale ( 1 reflected "no need for leadership at all" and 5 represented "the need for leadership a lot).

Human oriented leadership: Human oriented behavior of the leader reflects his actions towards having friendship, mutual trust, respect, and warmth in relationship between the leader and members of the group (Halpin, 1957). 
Task oriented leadership: The task oriented behaviors of the leader show that leader is involved in defining the relationship between himself and the members of his group, and in endeavoring to establish well-defined patterns of organization, channels of communication, and ways of getting the job done (Halpin, 1957).

The widely used leadership styles (i.e. human oriented and task oriented leadership) were measured through shortened version of Supervisory Behaviors Description Questionnaire (Fleishman, 1972). Total 16 items (8 each for human oriented and task oriented leadership) were adopted from reduced version of SBDQ (Supervisory Behavior Description Questionnaire). The reliability score for task oriented leadership was 0.76 and for human oriented leadership, it came out 0.80 .

Charismatic Leadership: Charismatic leadership is the ability to positively influence others through a compelling vision that deviates from the status quo and encouraging the followers to be independent thinker. Total 8 items were adopted to measure the charismatic leadership from Bass et al. (1995). The cronbach alpha remained 0.77.

Leader's expertise: Leader's expertise reflects the extent to which the leader is expert in all related areas of his section/unit. Leader's expertise scale is adopted from Podsakoff, Todor, and Schuler (1983) and 3 items were selected to measure leader's expertise. The reliability score remained 0.59 for these three items.

All the items related to leadership characteristics were measured on likert scale (strongly disagree " 1 " to strongly agree " 5 ").

\subsection{Outcomes Criteria}

Employees' Performance: Self rated performance index was used to measure the performance of employee on current position e.g. quality of work, quantity of work, dependability, ability to learn, initiative. Self rated performance scale of Roe et al. (1995) was utilized to measure the performance of employees and total 6 items were adopted. The cronbach alpha value remained .75 for these items.

Satisfaction: Employee's degree of satisfaction with his/her current job was measured with the help of Minnesota Satisfaction Index. Total 4 items were selected to measure the attitude of employees towards his/her job and the value of cronbach alpha was .65 for this measure.

Organizational Commitment: Organizational Commitment is defined as willingness to strive toward internalized organizational goals and desire to remain a member. The scale measuring organizational commitment consisted of 6 items and cronbach alpha was .72 for these items. Items measuring organizational commitment are adopted from revised version of Taillieu (1987).

Statistical results of the study are summed up in the next section.

\section{STATISTICAL RESULTS}

The moderator effects of need for leadership on the relationship between leadership characteristics and outcomes are explored using moderated multiple regression analysis. For this purpose, predictors were standardized first and then their interaction term was calculated by multiplying the standardized scores of both variables.

In order to determine the effect of need for leadership, following procedure was adopted.
$\mathrm{Y}=\beta_{0}+\beta_{1} \mathrm{X}_{1}+€$
Step I

Where Y represents the work outcomes (performance, job satisfaction and organizational commitment) separately and $\mathrm{X}_{1}$ represents the standardized scores of leadership characteristics (human oriented, task oriented, leader's expertise and charismatic leadership) separately. $\beta_{0}$ and $\beta_{1}$ are regression coefficients and $€$ is error term.

$$
\mathrm{Y}=\beta_{0}+\beta_{1} \mathrm{X}_{1}+\beta_{2} \mathrm{X}_{2}+€ \quad \text { Step II }
$$



for leadership.

Where $\mathrm{X}_{2}$ stands for standardized scores of followers' need for leadership and $\beta_{2}$ is the coefficient of need $\mathrm{Y}=\beta_{0}+\beta_{1} \mathrm{X}_{1}+\beta_{2} \mathrm{X}_{2+} \beta_{3} \mathrm{X}_{3}+€ \quad$ Step III

Where $\mathrm{X}_{3}$ represents the interaction term $\left(\mathrm{X}_{3}=\mathrm{X}_{1} * \mathrm{X}_{2}\right)$ of the standardized scores of followers' need for leadership and leadership characteristics separately.

Moreover, in order to determine the effect of high and low need for leadership, the need for leadership was dichotomized; as one standard deviation above of the mean (+1) representing the high need for leadership and one standard deviation below of the mean showing (-1) low need for leadership. These scores were entered in complete regression equation separately and new $\beta$ s of leadership characteristics were calculated separately. The following table summarizes the effects of high and low degrees of need for leadership in combination of leadership characteristics on work outcomes.

Table 4.1: Effects of Low and High Degrees of Need for leadership on the Relationship between Leadership Characteristics and Outcomes.

\begin{tabular}{|c|c|c|}
\hline \multirow{2}{*}{ Interaction Effects } & \multicolumn{2}{|l|}{ Need for Leadership } \\
\hline & High Degree & Low Degree \\
\hline $\begin{array}{l}\text { Substitute } \\
\left(\beta_{2}>0, \beta_{3}<0\right)\end{array}$ & Low effect on outcomes & High effect on outcomes \\
\hline $\begin{array}{l}\text { Enhancer } \\
\left(\beta_{2}>0, \beta_{3}>0\right)\end{array}$ & High effect on outcomes & Low effect on outcomes \\
\hline $\begin{array}{l}\text { Simple Positive Moderator } \\
\left(\beta_{2}=0, \beta_{3}>0\right)\end{array}$ & High effect on outcomes & Low effect on outcomes \\
\hline $\begin{array}{l}\text { Simple Negative Moderator } \\
\left(\beta_{2}=0, \beta_{3}<0\right)\end{array}$ & Low effect on outcomes & High effect on outcomes \\
\hline
\end{tabular}

These relationships are only true when $\beta_{1}>0$ i.e. (leadership is positively related to outcomes)

" 0 " indicates statically insignificant relationship given below.

Empirical results of need for leadership in connection with leadership characteristics on work outcomes are

Table 4.2 presents the statistical results of the need for leadership in connection with leadership characteristic (charismatic leadership, human oriented leadership, task oriented leadership and leader's expertise) on followers' performance separately.

Table 4.2 (A, B \& C) shows that three (3) out of 4 interaction effects are found statistically significant. In case of human oriented and charismatic leadership, need for leadership is found as substitute of the relationship between these leadership characteristics and followers' performance. This shows in case of high need for leadership among followers, these leadership characteristics will not add any significant effect on followers' performance. However, in case of task oriented leadership with performance, need for leadership is found as enhancer of the relationship showing that in case of high need for leadership among followers, task oriented leadership is found as instrumental in enhancing the followers' performance.

In last case, no statistically significant interaction effect was found between leader's expertise and need for leadership, but in this case need for leadership is found as simple positive predictor of followers' performance.

Table 4.3 presents the empirical results of impact of need for leadership in connection with leadership characteristic (charismatic leadership, human oriented leadership, task oriented leadership and leader's expertise) on followers' job satisfaction separately. 
Table 4.2: Moderator Effect of Need for Leadership on Leadership Characteristics and Employees' Performance

\begin{tabular}{|c|c|c|c|c|}
\hline \multicolumn{5}{|l|}{ Criterion: Employees' Performance } \\
\hline Variables & $\mathbf{R}_{\text {adj. }}^{2}$ & $\Delta \mathbf{R}^{2}$ & $\Delta \mathbf{F}$ & $\boldsymbol{\beta}$ \\
\hline \multicolumn{5}{|l|}{ A } \\
\hline Charismatic Leadership (CL) & .114 & .118 & 37.71 & $.22 * * *$ \\
\hline Need for Leadership (NLP) & .218 & .106 & 38.47 & $.33 * * *$ \\
\hline Interaction $(C L \times N L P)$ & .228 & .012 & 4.49 & $-.12 *$ \\
\hline \multicolumn{5}{|l|}{ B } \\
\hline Human-Oriented Leadership (HL) & .188 & .191 & 66.66 & $.31 * * *$ \\
\hline Need for Leadership (NLP) & .253 & .067 & 25.56 & $.26 * * *$ \\
\hline Interaction $(H L \times N L P)$ & .265 & .014 & 5.37 & $-.12 *$ \\
\hline \multicolumn{5}{|l|}{$\mathbf{C}$} \\
\hline Task-Oriented Leadership (TL) & .170 & .173 & 58.96 & $.24 * * *$ \\
\hline Need for Leadership (NLP) & .230 & .062 & 22.76 & $.29 * * *$ \\
\hline Interaction $(T L \times N L P)$ & .238 & .010 & 3.78 & $.10^{\circ}$ \\
\hline \multicolumn{5}{|l|}{ D } \\
\hline Leader's Expertise (LX) & .138 & .141 & 46.60 & $.22 * * *$ \\
\hline Need for Leadership (NLP) & .241 & .105 & 39.40 & $.34 * * *$ \\
\hline Interaction $(L X \times N L P)$ & .244 & .006 & 2.34 & -.08 \\
\hline
\end{tabular}

$* * * p<0.001, * * p<.01, * p<.05,{ }^{\circ} p<.10$

$\Delta R^{2} \quad$ Net variance explained by that particular variable

$\beta \quad$ Standardized $\beta$

Table 4.3: Moderator Effect of Need for Leadership on Leadership Characteristics and Employees' Job Satisfaction Criterion: Job Satisfaction

\begin{tabular}{|c|c|c|c|c|}
\hline \multicolumn{5}{|l|}{ Criterion: Job Satisfaction } \\
\hline & $\mathbf{R}_{\text {adj. }}^{2}$ & $\Delta \mathbf{R}^{2}$ & $\Delta \mathbf{F}$ & $\boldsymbol{\beta}$ \\
\hline \multicolumn{5}{|l|}{ A } \\
\hline Charismatic Leadership (CL) & .110 & .113 & 36.17 & $.28 * * *$ \\
\hline Need for Leadership (NLP) & .151 & .044 & 14.87 & $.19 * *$ \\
\hline Interaction $(C L \times N L P)$ & .184 & .036 & 12.44 & $-.20 * * *$ \\
\hline \multicolumn{5}{|l|}{ B } \\
\hline Human-Oriented Leadership (HL) & .144 & .147 & 48.81 & $.31 * * *$ \\
\hline Need for Leadership (NLP) & .170 & .028 & 9.69 & $.15^{*}$ \\
\hline Interaction $(H L \times N L P)$ & .190 & .023 & 8.103 & $-.16^{* *}$ \\
\hline \multicolumn{5}{|l|}{$\mathbf{C}$} \\
\hline Task-Oriented Leadership (TL) & .122 & .125 & 40.23 & $0.23 * *$ \\
\hline Need for Leadership (NLP) & .144 & .025 & 8.41 & $.18 * *$ \\
\hline Interaction $(T L \times N L P)$ & .157 & .016 & 5.21 & $-.13 *$ \\
\hline \multicolumn{5}{|l|}{ D } \\
\hline Leader's Expertise (LX) & .131 & .134 & 44.17 & $.26 * * *$ \\
\hline Need for Leadership (NLP) & .169 & .041 & 14.03 & $.20 * *$ \\
\hline Interaction $(L X \times N L P)$ & .181 & .014 & 5.01 & $-.12 *$ \\
\hline
\end{tabular}

Table 4.3 (A, B, C \& D) shows that in all above four cases interactions effect are found statistically significant. In all four cases, need for leadership is found a substitute of the relationship between leadership characteristics and followers' satisfaction. It means that in case of high need for leadership among employees, there is less strong relationship between leadership characteristics and followers' satisfaction.

Table 4.4 presents the statistical results of impact of need for leadership in connection with leadership characteristic (charismatic leadership, human oriented leadership, task oriented leadership and leader's expertise) on followers' organizational commitment separately. 
Table 4.4: Moderator Effect of Need for Leadership on Leadership

Characteristics and Employees' Organizational Commitment

Criterion: Organizational Commitment

\begin{tabular}{|c|c|c|c|c|}
\hline Variables & $\mathbf{R}_{\text {adj. }}^{2}$ & $\Delta \mathbf{R}^{2}$ & $\Delta \mathbf{F}$ & $\beta$ \\
\hline \multicolumn{5}{|l|}{ A } \\
\hline Charismatic Leadership (CL) & .115 & .118 & 38.17 & $.31 * * *$ \\
\hline Need for Leadership (NLP) & .112 & .000 & .001 & .03 \\
\hline Interaction $(C L \times N L P)$ & .122 & .013 & 4.20 & $.12 *$ \\
\hline \multicolumn{5}{|l|}{ B } \\
\hline Human-Oriented Leadership (HL) & .130 & .133 & 43.63 & $.36^{* * *}$ \\
\hline Need for Leadership (NLP) & .128 & .001 & .216 & .01 \\
\hline Interaction $(H L \times N L P)$ & .146 & .021 & 7.06 & $.15 * *$ \\
\hline \multicolumn{5}{|l|}{$\mathrm{C}$} \\
\hline Task-Oriented Leadership (TL) & .069 & .072 & 22.10 & $.28 * * *$ \\
\hline Need for Leadership (NLP) & .066 & .000 & .002 & .01 \\
\hline Interaction $(T L \times N L P)$ & .074 & .011 & 3.74 & $.11^{\circ}$ \\
\hline \multicolumn{5}{|l|}{ D } \\
\hline Leader's Expertise (LX) & .143 & .146 & 48.86 & $.41 * * *$ \\
\hline Need for Leadership (NLP) & .140 & .000 & .043 & .01 \\
\hline Interaction $(L X \times N L P)$ & .160 & .023 & 7.75 & $.16^{* *}$ \\
\hline
\end{tabular}

Table 4.4 (A, B, C \& D) reveals that in the above four cases, all interactions effects are statistically significant. The relationship of the need for leadership on all four leadership facets and organizational commitment is found as simple positive moderator of the relationship between leadership characteristics and followers' commitment. This means in case of followers having high need for leadership, there will be strong relationship between leadership characteristics and employees' commitment.

\section{DISCUSSION AND CONCLUSION}

This study has investigated the moderator effect of need for leadership among followers in relation with leadership characteristics on followers' work related outcomes for two basic reasons. First, to what extent, the results of moderator effect in leadership research are improved using the single moderator variable. Second, to what extent these results are beneficial for practicing managers. Therefore, the results of the study will be discussed from two different perspectives. Considering the first objective, the statistical results have fully supported it. Total 12 possible moderator relations were tested. Out of 12 moderator relationships of need for leadership with leadership characteristics and outcomes, 11 are statistically significant. In this way, need for leadership moderated 11 out of 12 times. This percentage (91\%) is far better than the de Vries' (1997) studies, where in 52\% of the cases moderator effects of need for leadership were found. While, comparing the results of need for leadership (which has used single moderator variable) with substitutes for leadership (which has offered more than one moderator variable), the need for leadership has moderated $71 \%$ of the cases, however the substitutes for leadership has moderated 9.3\% (de Vries, 1997, p. 49) of the cases.

Second, on theoretical ground, this theory seems to be an ideal theory in defining the effectiveness of leader i.e. every employee will be given leadership based on the degree and type of his need for leadership. This leadership practice will produce more successful outcomes without wastage of any extra energy. Hence, the empirically results have partially supported this objective. In case of followers' performance, only one interaction term of task oriented leadership and need for leadership is found positive showing that banking employees desire such kind of leadership which is instrumental in enhancing their performance. This is especially true in case of banking followers, where employees and management are concerned with the goal achievement. Moreover, in cases of followers' satisfaction, all the four interaction terms are negatively related to the followers' satisfaction. This is some what embarrassing situation. On one hand, these results have shown that need for leadership exist among employees. On the other hand, when leadership is given to followers to satisfy their need for leadership, but need for leadership itself has negated the leadership influence. Furthermore, in case of commitment, all the four interaction terms of leadership 
characteristics and need for leadership are positively related to the followers' commitment. This indicates, when followers' needs pertaining to their leaders are fulfilled, as a result they are more committed followers than those whose leadership needs are not satisfied.

For the practitioners, the results of the study are strongly convincing since they must understand the need for leadership of their followers before exercising their leadership practices. Moreover, for future researchers, this theory seems promising and demands more research to be satisfactorily convincing.

\section{AUTHOR INFORMATION}

Prof. Dr. Mahmood A Bodla is working as the Director of COMSATS Institute of Information Technology Sahiwal Campus, Pakistan. His research areas include, human resource management, econometrics, and change management.

Ghulam Hussain is working as lecturer in Department of Management Sciences, CIIT Sahiwal. His research areas include human resource management and leadership.

\section{REFERENCES}

1. Agho, A. O., Price, J.L. \& Mueller, C.W. (1992). Discriminant validity of measures of job satisfaction, positive affectively and negative affectively. Journal of Occupational and Organizational Psychology, 65, $185-196$.

2. Bass, B.M. \& Avolio, B.J. (1995). The Multifactor Leadership Questionnaire (5x-Short), Mind Garden, Redwood City, CA.

3. De Vries, R.E. (1997). Need for Leadership: A solution to empirical problems in situational theories of leadership. PHD Dissertation Tilburg University. Tilburg.

4. De Vries, R.E., Roe, R.A., \& Taillieu, T.C.B. (2002). Need for Leadership as moderator of the relationship between leadership and individual outcomes. The Leadership Quarterly, 13, $121-137$.

5. De Vries, R.E., Roe, R.A., \& Taillieu, T.C.B. (1999). On Charisma and Need for Leadership, European Journal of Work and Organizational Psychology, 8(1), 109 - 133.

6. Fleishman, E.A. (1972). Manual for supervisory behavior description questionnaire. Washington, Dc: American Institute for Research.

7. Halpin, A.W. \& Winer, B.J. (1957). A factorial study of the leader behavior description. In R.M. Stogdill \& A.E (Eds). Leader behavior: Its description and measurement. Columbus: Ohio State University.

8. House R.J. (1971). A path goal theory of leadership. Administrative Science Quarterly, 16, 321 - 338.

9. Howell, J.P. \& Dorfman, P.W. (1986). Leadership and substitutes for leadership among professional and nonprofessional workers. Journal of Applied Behavioral Science, 22, 29 - 46.

10. Howell, J.P., Dorfman, P.W., \& Kerr, S. (1986). Moderator variables in leadership research. Academy of Management Review, 11, $88-102$.

11. Kerr, S. \& Jermier, J.M. (1978). Substitutes for leadership: Their meaning and measurement. Organizational Behavior and Human Performance, 22, 375 - 403.

12. Maslow, A.H. (1943). A Theory of Human Motivation, Psychological Review, 50(4), 370-96.

13. McClelland, D.C. 1955. Studies in Motivation. Appleton.

14. Podsakoff, P.M., Todor, W.D., \& Schuler, R.S. (1983). Leader expertise as a moderator of the effects of instrumental and supportive leader behaviors. Journal of Management, 9, $173-185$.

15. Roe, R.A., Diens, E., Ten Horn, L. \& Zinvieva, I. (1995). Expanded Delft Measurement Kit - English version, Tilburg: WORC

16. Taillieu, T.C.B. (1987). Meaning of work: Relationships between personal and contextual factors. Research Meeting for the European Committee for work and Pay.

17. Villa, J.R., Howell, J.P., Dorfman, P.W., \& Daniel, D.L. (2003). Problems with detecting moderators in leadership research using moderated regression. The Leadership Quarterly, 14, 3 - 23. 